\title{
Mechanical Properties and Durability of Concrete with Water Cooled Copper Slag Aggregate
}

\author{
Maria Mavroulidou ${ }^{1}$ iD
}

Received: 1 May 2016 / Accepted: 22 December 2016 / Published online: 27 January 2017

(c) The Author(s) 2017. This article is published with open access at Springerlink.com

\begin{abstract}
Copper slag is a voluminous waste material obtained during the manufacturing of copper (matte smelting process). As its disposal becomes a concern for environmental protection agencies and governments, possible alternative outlets for this waste material are needed. The paper presents a laboratory study on CEM-II concrete mixes, containing water-cooled copper slag waste material for a partial or full replacement of fine concrete aggregate. A series of tests were performed at two different water to cement ratios, to determine the workability, cube compressive strength, indirect tensile strength, static modulus of elasticity, and a number of durability-related characteristics (water absorption, accelerated corrosion, carbonation, alkali-silica reaction). The results showed that water-cooled copper slag had variable effects on the resulting fresh or hardened concrete properties, depending on the sand replacement level and water to cement ratio. However the measured strength values were likely to be linked to the usual variability of concrete batches, rather than a significant effect of the copper slag aggregate. This hypothesis was further supported by statistical analysis. Concerning the durability related characteristics, the overall performance of the concrete containing copper-slag was in most cases similar or better than that of normal concrete with natural sand aggregate. Based on the results water-cooled copper slag can therefore be considered to be a suitable fine aggregate for concrete. This shows promise for developing
\end{abstract}

Maria Mavroulidou

mavroum@1sbu.ac.uk

Division of Civil and Building Services Engineering (BEA), London South Bank University, 103 Borough Road, London SE1 0AA, UK an additional viable solution to tackle the issue of copper slag waste.

Keywords Industrial solid waste management . Concrete $\cdot$ Waste copper slag aggregate $\cdot$ Mechanical properties · Durability

\section{Introduction}

Industrial operations produce large quantities of waste materials. An example is copper slag (CS), a voluminous waste material obtained during the manufacturing of copper. The extraction of copper from sulphide ores usually involves flotation followed by smelting and refining operations to produce pure copper metal. The major constituents of a copper smelting charge are sulphides and oxides of iron and copper; other constituents include $\mathrm{SiO}_{2}, \mathrm{Al}_{2} \mathrm{O}_{3}$, $\mathrm{CaO}$ and $\mathrm{MgO}$ (either present in the original concentrate or added as flux) [1]. Two distinct liquid phases are thus formed: copper-rich matte (a sulphide-rich phase) and copper slag (an oxide-rich phase, also known as ferro-sand). While copper-matte liquid is settling down in the smelter due to its higher density, smears of copper slag are segregated and remain on the surface (also in liquid form). These are then removed and cooled. Slow air-cooling creates a hard and crystalline product while fast cooling in water produces amorphous, glassy granulates [1]. The utilization and disposal of this waste CS becomes a concern for environmental protection agencies and governments, as to obtain 1 ton of clear copper 2.2-3 million tons of CS are produced [1], with an annual worldwide production of copper recently reported to be approximately 35 million tonnes [2]. Due to the increasing problem, a number of studies showed many possibilities of how this material could 
be reused or recycled. For slags containing appreciable amounts of metals a first viable option is the metal recovery by various processes, including electric arc furnace smelting, leaching and flotation. However the metals contained in the copper slag are often at very small amounts and their recovery may not be economical. Instead other uses of the copper slag were explored and adopted, for instance in abrasive or cutting tools, pavements, tiles, glass, roofing granules, etc. [3]. Due to its physical and chemical characteristics an alternative possible application for this material could be its use as aggregate and probably also cement replacement in concrete production. This is a promising application, as concrete is the most widely used material in construction after water, thus providing an ideal opportunity for the recycling of waste materials in large quantities. In general however aggregate properties influence the freshly mixed and hardened concrete properties. Concrete aggregate must be clean and free of objectionable materials, which can affect the bonding of the cement paste to the aggregate or be corrosive to metal reinforcement. It must be strong, hard and durable, uniformly graded and falling within certain upper and lower bounds of grading. Extensive studies and evidence of good performance are therefore needed before a new material can be adopted with confidence for concrete production at an industrial scale. In this respect copper slag as concrete aggregate appears to be less well researched compared to other waste materials. A further complication is that slag varies not only in form (crystalline vs. amorphous) according to the cooling process but also in its chemical composition (this can vary according to the furnace type, the metallurgical production process, the composition of the extracted ore, etc. [4]), which could potentially have varied effects on the resulting concrete properties. An important point to note is that CS has been excluded from the hazardous waste lists of the United States Environmental Protection Agency as well as the United Nations (UN) Basel Convention on the Transboundary Movement of Hazardous Waste and its Disposal [4]. Further studies confirmed that the heavy metals present in the slag are stable and are not likely to dissolve significantly even through repetitive leaching under acid rain in a natural environment, and that the highest concentration of all the elements was reported to be far below the prescribed limits in USEPA 40CFR Part 261 (e.g. [5, 6]; the latter paper reported that the National council for cement and building materials in New Delhi India, found that the leaching of heavy metals from copper slag samples was well below the toxicity limits even under aggressive conditions). There should therefore be no serious concerns regarding the leaching of toxic elements if copper slag was used in large-scale construction.

A literature review on concrete containing copper slag was performed at the beginning of this research. The summary of this review is reported below, in terms of concrete sand replacement only (i.e. not coarse aggregate replacement as e.g. in [7, 8] or cement replacement as e.g. in $[9,10]$; also papers reporting results on mortars, e.g. [11] are excluded). Only primary material is reported, which excludes recent review papers such as [12]-[15] and a review book on copper slag as a construction material, published while this manuscript was under review [16]. From the literature review, it transpired that most research to-date studied one type of slag (either air-cooled CS or water-cooled CS). It was also noticed that in many papers the type of slag used was not explicitly mentioned (e.g. [17-22]) but that overall the air-cooled slag appears to be the type of slag used in most publications; this is either mentioned explicitly (e.g. [6, 23-25]-the latter paper uses both air cooled and water cooled slag for the partial replacement of coarse and fine aggregate respectively-) or can be inferred based on the supplier's details and material characteristics (e.g. specific gravity). On the other hand the water cooled slag appears to have been studied to a lesser extent: of the reviewed papers only in one paper it was implied that slag was perhaps water cooled. Namely Kharade et al. [26] describing the industrial process producing copper slag, (without specifying that this was the process followed by their slag supplier), mentioned that slag 'is transported to a water basin with a low temperature for solidification' (note however that Poovizhi and Khatirvel [24] using slag from the same supplier mentioned this explicitly to be air-cooled). The slag used in Al-Jabri et al's publications [17-20] was possibly water-cooled based on information found directly from the suppliers' current website (assuming that the current industrial processes described on the website were the same at the time of $\mathrm{Al}$ Jabri et al's research). Some papers used copper tailings to replace sand aggregate $[27,28]$; these are not directly comparable to the water-cooled aggregate used in the present study. In the literature the slag was used to replace either fine or coarse concrete aggregates, thus further reducing the amount of the available experimental evidence for each type of slag and aggregate type respectively. Moreover, a number of related publications were published in national society journals and were not written in English (e.g. [29, 30]). A number of the existing studies assessed concrete strength with copper slag as partial sand replacement of up to $40-50 \%$ (e.g. $[21,24]$ etc.); some other papers proceeded to full sand replacement (e.g. [17-20, 26, 31]). In some of the latter papers (i.e. $[17,18,19,31])$ special types of concrete were tested, involving the use of additional materials (e.g. silica fume and superplasticisers) compared to normal concrete. Based on these papers copper-slag concrete was reported to have similar or even higher strengths than normal concrete at least for modest sand replacements of about 20-40\%; however this increase was usually followed by a 
loss in strength so that for high slag contents the strength of the concrete with copper slag is lower than the control (no copper slag) mixes [17-20, 26, 31]. Very few papers assessed workability of the copper-slag concrete. Generally it was found that copper slag may increase workability of concrete mixes (e.g. [17-20, 31]) but most of these papers used superplasticizers to enhance workability of high strength concrete mixes; also in one paper [26] the slump was found to slightly increase with copper slag percentage but overall it remained very low despite the fairly high water/cement ratio $(\mathrm{w} / \mathrm{c}=0.48)$. No measured data of moduli of elasticity were found in the literature, except in a Japanese paper as reported by [2]. Finally, there is little information widely available on various durability aspects of concrete with copper-slag fine aggregate, with few exceptions [e.g. 6, 23, 25]. In the former two papers concrete sand was partially replaced by copper slag and the water absorption, corrosion of reinforcement, chloride permeability and acid and sulphate resistance of the resulting concrete were studied. It was found that concrete with copper slag had a lower chloride permeability (that the authors linked to a decreased porosity of the concrete). However a slightly lower acid resistance and slightly higher corrosion and water absorption rates were observed. The latter paper used CEM-I cement and considered both coarse aggregates replacement by air cooled copper slag at 20 and $40 \%$ volume replacements as well as fine aggregate replacement by copper slag at 20 and $40 \%$ levels per volume. It studied gas permeability of copper slag concrete (which was significantly lower or comparable to that of the control mix), chloride ingress (which was found to be significantly lower for copper slag mixes), freeze-thaw resistance to de-icing agents (which was significantly reduced compared to that of the control mix), and accelerated carbonation which occasionally showed only a slight increase of the carbonation depth (locally) when using copper slag but was still acceptable. Durability was also linked to the study of the porosity of copper-slag concrete; the capillary porosity of copper slag concrete was found to be similar to that of normal concrete, whereas the effect of copper slag on the open porosity was found to be variable but still acceptable.

Due to the lack of extensive experimental evidence concerning in particular the durability aspects of this type of concrete, it has been reported that even in countries where copper slag aggregate has in principle been approved for construction projects, the use of copper slag in concrete production has been hindered [30]. Further studies are thus required to assess whether concrete with copper slag would satisfy the quality requirements for industrial production.

To address this research need, a comprehensive experimental programme was set out to study salient properties of concrete with water-cooled copper slag used as fine concrete aggregate at various concrete sand replacement levels,
Table 1 Chemical composition of the copper slag used in this study

\begin{tabular}{ll}
\hline Chemical composition & $\%$ \\
\hline $\mathrm{SiO}_{2}$ & $33.0-38.0$ \\
$\mathrm{FeO}$ & $43.0-55.0$ \\
$\mathrm{Al}_{2} \mathrm{O}_{3}$ & $3.0-7.0$ \\
$\mathrm{CaO}$ & $1.0-4.0$ \\
$\mathrm{MgO}$ & $1.0-2.0$ \\
$\mathrm{Na}_{2} \mathrm{O}$ & $0.1-0.5$ \\
$\mathrm{~K}_{2} \mathrm{O}$ & $0.1-0.5$ \\
$\mathrm{Cu}$ & $0.5-0.7$ \\
$\mathrm{Mn}$ & $0.2-0.4$ \\
$\mathrm{TiO}$ & $0.1-0.25$ \\
$\mathrm{~Pb}$ & $0.01-0.20$ \\
$\mathrm{Zn}$ & $1.0-2.0$ \\
$\mathrm{~S}$ & $0.5-1.0$ \\
$\mathrm{Cr}(\mathrm{III})$ & $0.1-0.24$ \\
$\mathrm{Cr}(\mathrm{VI})$ & $\mathrm{Nil}$ \\
$\mathrm{Free} \mathrm{Silica}$ & $<1.0$ \\
\hline
\end{tabular}

including full sand replacement. The first part of the experimental results, using cement type CEM-I, was recently presented in CEST2015 international conference [32]. This paper presents a second series of results also produced at London South Bank University, based on a different type of cement. These include data on properties such as modulus of elasticity that are lacking in the literature, and a study of various durability aspects of concrete containing water cooled copper slag, which were not discussed in Mavroulidou and Liya [32]. A statistical analysis on the compressive strength characteristics of the resulting concrete is then presented at the end of this paper to assess whether sand replacement by copper slag significantly affects the resulting concrete strength.

\section{Experimental Procedures, Materials and Mixes}

For this study the water-cooled copper slag was supplied by ScanGrit (brand name ScanGrit Iron Silicate Grade 5 i.e. of particle size ranging $0.2-2.5 \mathrm{~mm}$ ). According to the supplier's description it is an inert synthetic mineral manufactured by granulation in water of the slag arising from unique fumed copper smelting processes. It is an iron silicate with trace metals bound in an amorphous glass form as complex silicates and oxides and contains no free silica; it also has a chloride content of $<15 \mathrm{ppm}$. Its detailed chemical composition according to the supplier is presented in Table 1 . The particle density and water absorption characteristics of the copper slag compared to those of river sand were determined using BS 812-2: 1995, Method 5 [33]. 
Table 2 Physical

characteristics of the copper slag and river sand used in this study

\begin{tabular}{lll}
\hline & Copper slag & River sand \\
\hline $\begin{array}{l}\text { Particle shape } \\
\text { Texture }\end{array}$ & Angular* & Subrounded* \\
Colour & Glassy-Smooth* & Smooth* \\
& Black & $\begin{array}{c}\text { Varied (mostly very } \\
\text { pale brown and }\end{array}$ \\
& & yellow) \\
Odour & None & None \\
Particle density (oven dried) $-\mathrm{Mg} / \mathrm{m}^{3}$ & 3.73 & 2.56 \\
Particle density (sat. surf. dried)—-Mg/m & 3.73 & 2.59 \\
Particle density (apparent)- $\mathrm{Mg} / \mathrm{m}^{3}$ & 3.74 & 2.63 \\
Water absorption - \% & 0.11 & 1.06 \\
Fineness modulus & 2.97 & 2.98 \\
\hline
\end{tabular}

*As assessed by visual inspection using a magnifying loop and the feel method
Table 3 Chemical composition of limestone cement used in this study

\begin{tabular}{llllllllll}
\hline $\mathrm{SiO}_{2}$ & $\mathrm{Al}_{2} \mathrm{O}_{3}$ & $\mathrm{Fe}_{2} \mathrm{O}_{3}$ & $\mathrm{CaO}$ & $\mathrm{MgO}$ & $\mathrm{SO}_{3}$ & $\mathrm{~K}_{2} \mathrm{O}$ & $\mathrm{Na}_{2} \mathrm{O}$ & $\mathrm{EqNa}_{2} \mathrm{O}$ & $\mathrm{LOI}$ \\
\hline 18.3 & 4.7 & 2.2 & 62.3 & 0.8 & 2.8 & 0.5 & 0.4 & 0.5 & 7.5 \\
\hline
\end{tabular}

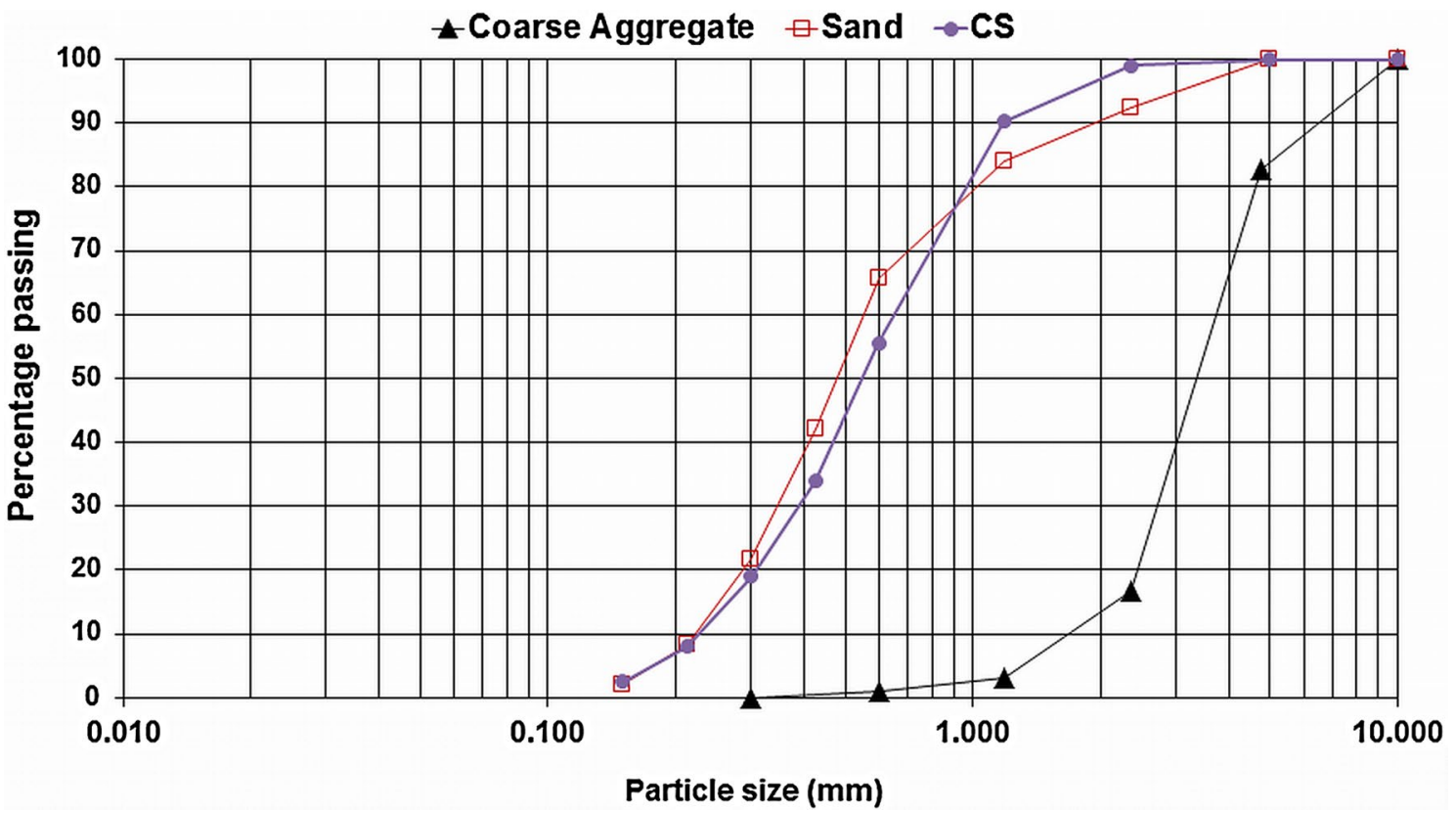

Fig. 1 Particle size distribution of the aggregates used in the mixes

These are shown in Table 2 together with other physical characteristics of the two materials.

As opposed to Mavroulidou and Liya who used CEM-I [32], in this study the cement used was limestone Portland Cement (CEM-II/A-L 32,5R) obtained from Lafarge-UK (note that in the UK CEM-I has been increasingly replaced with less $\mathrm{CO}_{2}$ intensive CEM-II products). The typical chemical composition of this cement provided by the supplier is shown in Table 3. The fine aggregate was concrete sand of a maximum size of $5 \mathrm{~mm}$; the coarse aggregate was crushed mixed gravel of a maximum size of $10 \mathrm{~mm}$ (brand name Tarmac Trupak). The particle size distribution of the aggregates (coarse concrete aggregate and fine concrete aggregate or copper slag) used in the mixes was determined using the dry sieving test (see Fig. 1). It can be seen that the sand and copper slag materials had a very similar grading, with $\mathrm{D}_{90}$ of 1.2 and $1.9 \mathrm{~mm}$ for the copper slag and sand respectively, $\mathrm{D}_{50}$ of 0.47 and $0.54 \mathrm{~mm}$ for the sand 
Table 4 Mix design proportions $\left(\mathrm{kg} / \mathrm{m}^{3}\right)$ and mix ratio

\begin{tabular}{llllcl}
\hline Mix set & & CEM-II & Fine aggregate & $\begin{array}{l}\text { Coarse aggregate } \\
(10 \mathrm{~mm})\end{array}$ & Water \\
\hline 1 & Proportions $\left(\mathrm{kg} / \mathrm{m}^{3}\right)$ & 397 & 595 & 1190 & 218 \\
& Ratio & 1 & 1.5 & 3 & 0.55 \\
2 & Proportions $\left(\mathrm{kg} / \mathrm{m}^{3}\right)$ & 403.5 & 605 & 1210 & 181.5 \\
& Ratio & 1 & 1.5 & 3 & 0.45 \\
\hline
\end{tabular}

and copper slag respectively and $\mathrm{D}_{10}$ of $0.22 \mathrm{~mm}$ for both materials, and a coefficient of uniformity of 2.91 and 2.51 for the slag and sand respectively. This confirms the suitability of the slag for use as fine concrete aggregate from the point of view of gradation. It also implies that the grading would in principle be maintained consistent when mixing the two materials hence giving adequate mixes without the need to take extra precautions.

Concrete was made with a mix design of 1:1.5:3 (1 part cement; 1.5 parts sand and 3 parts coarse aggregate) according to British Standards guidelines for RC40 [34]. Two different sets of mixes were made with water/cement (w/c) ratios of 0.55 and 0.45 respectively, with the mix composition shown in Table 4. Mixes without copper slag were made to serve as control mixes. Copper slag was then used at increasing percentages per total sand mass to replace regular concrete sand (fine aggregate). For consistent comparisons when assessing the effect of the copper slag on the different concrete properties, the w/c ratio was kept constant when the sand was partly or fully replaced by copper slag (i.e. w/c of 0.55 and 0.45 respectively for the two sets of mixes). The mixing was in accordance with BS EN 12390-2:2009 [35] using a rotating mixer. First the aggregates and cement were mixed. Water was then gradually added during the first 30 s of mixing; after all the materials had been added, mixing continued for at least $2 \mathrm{~min}$ and not more than 3 min, until a homogeneous paste was obtained. Specimens were then cast in moulds in three separate layers; each layer was compacted on a vibrating table for approximately $15 \mathrm{~s}$, to remove any entrapped air bubbles from the mix (care was taken to avoid over-vibrating the mix, as this could lead to segregation). Specimens were demoulded $24 \mathrm{~h}$ after casting and water cured at a temperature of $20^{\circ} \mathrm{C}\left( \pm 2{ }^{\circ} \mathrm{C}\right)$ until testing. The workability of fresh concrete mixes was then assessed based on the measured slump of the mixes immediately after mixing, according to BS EN 12350-2:2009 [36]. The cube compressive strength (100 mm cubes) of the hardened concrete mixes at different curing times was determined according to BS EN 12390-3:2009 [37] using a Zwick Roell ToniPACT II $2000 \mathrm{kN}$ compression test plant. The tensile strength of mixes was determined based on two indirect testing methods: (a) the tensile splitting strength of $150 \mathrm{~mm}$ diameter and $300 \mathrm{~mm}$ height cylinders tested according to BS EN 12390-6:2009 [38] using the Zwick Roell ToniPACT II 2000kN compression test plant; (b) the flexural strength, also known as Modulus of Rupture (MoR), determined according to BS EN 12390-5:2009 [39] from two-point flexural strength tests on selected mix beams of $500 \mathrm{~mm}$ length and a section of $100 \mathrm{~mm}$ $\times 100 \mathrm{~mm}$. The static modulus of elasticity of selected mixes was determined on cylinders prior to splitting cylinder testing according to BS 1881-121:1983 [40]. A series of tests were performed to assess the durability of concrete mixes, namely water absorption by immersion, accelerated corrosion, carbonation and alkali-silica reaction testing. Water absorption testing shows how easily concrete will allow the penetration of liquids, which is undesirable, as it allows for the ingress of aggressive chemicals, leading to premature corrosion of reinforcing steel, spalling and deterioration of concrete. The water absorption tests were performed following the BS 1881122 guidelines [41] on 72-h oven-dried $100 \mathrm{~mm}^{3}$ concrete cubes (cured for 28 days), which were subsequently left to cool in a dry airtight vessel for $24 \mathrm{~h}$. The cubes were then completely immersed in water for $30 \mathrm{~min}$; the moisture absorption was calculated as the increase in the mass of the cube after immersion, expressed as a percentage of the mass of the dry cube. Due to the presence of a high amount of iron oxides in the slag it was also considered of relevance to assess the corrosion of resulting reinforced concrete. Corrosion of steel reinforcement is one of the major causes affecting the long-term performance of reinforced-concrete structures. As the process of steel corrosion is long, accelerated corrosion testing was performed using an impressed current density methodology (see e.g. [42]). The apparatus consisted in a $10 \mathrm{~V}$ DC power supply, a data logger, two stainless steel plates (marine grade) and a container with $3.5 \%$ of $\mathrm{NaCl}$ solution. $100 \mathrm{~mm}$ cube samples were cast for the two studied w/c ratios of 0.45 and 0.55 respectively. The copper slag content tested was CS $0 \%$, CS $60 \%$ and CS $100 \%$. During casting a pre-weighed metal bar of a diameter of $8 \mathrm{~mm}$ was fixed at the centre of the concrete cube specimens. The samples were cured in a water tank for 7 days, consistently with the curing of other hardened concrete specimens. They were subsequently subject to a constant 


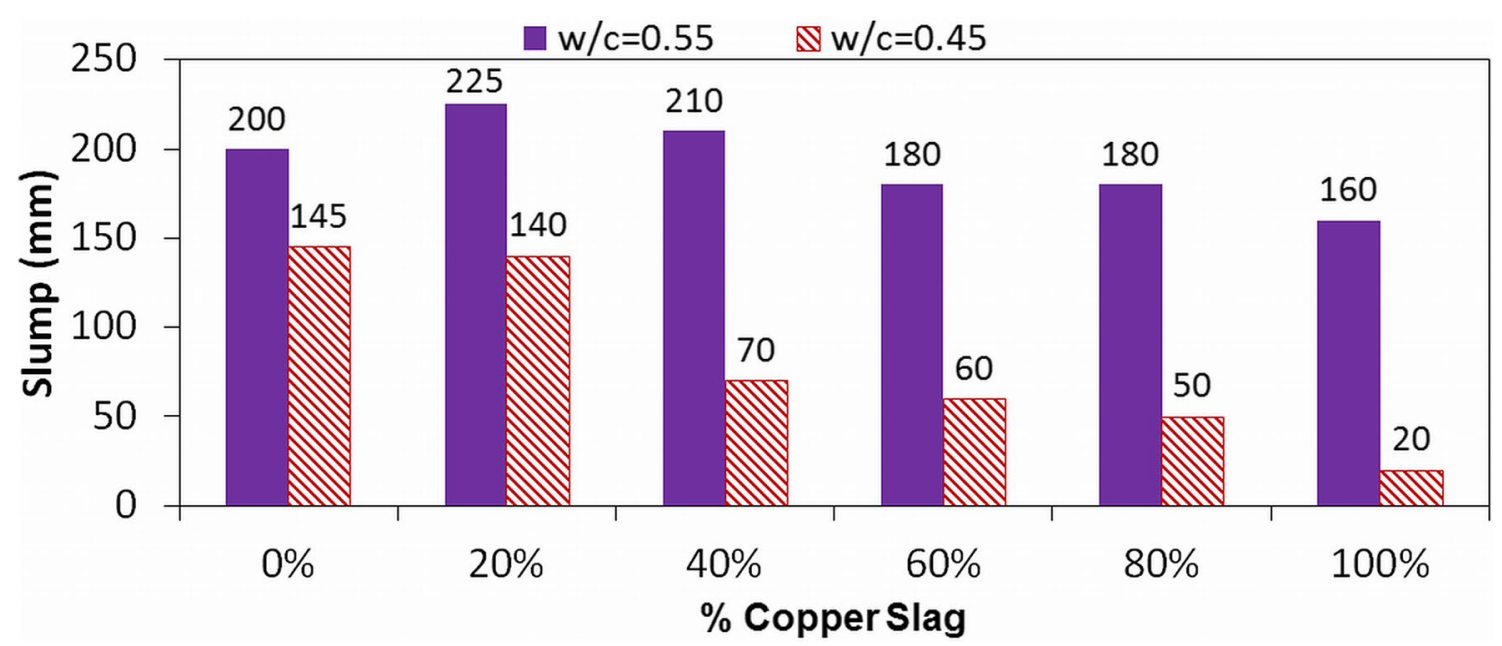

Fig. 2 Slump testing results

immersion into the $\mathrm{NaCl}$ solution for 21 days. During the test the steel bar was connected to the positive terminal whereas the negative terminal was connected to the stainless steel plates. After 21 days the specimens were removed and the metal bars were separated from the concrete. The metal bars were cleaned according to ASTM G1-90 standard [43], using a solution of $500 \mathrm{ml}$ of hydrochloric acid 5\% with $3.5 \mathrm{~g}$ of hexamethylenetetramine in water to obtain a solution volume of $1000 \mathrm{ml}$. The percentage of the actual amount of steel lost in corrosion was then calculated gravimetrically by weighing the cleaned bars and assessing their mass loss compared to the original bar mass before testing. Carbonation testing was performed using the phenolphthalein indicator method according to BS EN 14630: 2006 [44]. Carbonation can destroy the alkaline environment of concrete, which protects embedded steel reinforcement from corrosion. To assess possible carbonation problems, freshly cut cores of specimens were sprayed with a phenolphthalein $\mathrm{pH}$ indicator solution $(1 \mathrm{~g}$ phenolphthalein in $70 \mathrm{ml}$ ethyl alcohol diluted to $100 \mathrm{ml}$ with distilled water) and measurements taken within $30 \mathrm{~s}$ after spraying [44]. These were specimens left for 10 months in outdoors environment, partly protected by a roof (i.e. natural environment carbonation conditions). Finally, accelerated alkali-silica reaction testing was performed on mortar bars according to ASTM C1260 [45] guidelines. The only difference was that due to health and safety reasons the prescribed temperature in the $\mathrm{NaOH}$ solution bath was lowered during the night time. To compensate for this, the test was run for longer than the specified 14 days. Quadruple specimens per mix per curing time were cast for the cube compressive strength (the most important property of concrete, on which common concrete element design is based), whereas indirect tensile strength and durability testing samples were cast in duplicate.

\section{Experimental Results}

\section{Fresh Concrete Workability}

A possible anticipated difficulty when using aggregate other than that recommended for concrete could be the effect on the workability of the fresh concrete. As this research is a parametric study to assess the effects of copper slag on various properties of concrete, we chose not to adjust the mix in order to get a fixed slump (e.g. by adjusting water content and using superplasticisers). Instead we systematically observed the changes in the slump of the mixes upon replacements of sand by copper slag at constant steps. Figure 2 presents results of the slump tests for each copper slag percentage for the two different $w / c$ ratios used. These showed that all $0.55 \mathrm{w} / \mathrm{c}$ mixes had high $(100-175 \mathrm{~mm})$ to very high slumps (above $175 \mathrm{~mm}$ ) and hence workability; however in most cases the slumps of mixes including copper slag were lower to those of the control mixes, in particular for a water/cement ratio of 0.45 , which for high percentages of copper slag showed low to very low workabilities (slumps below $50 \mathrm{~mm}$ ), which would be inadequate for a number of practical uses. This finding goes against the original assumptions made that the lower water absorption of the copper slag aggregate would cause higher slumps than those of the control mixes. It is possible that slumps were affected to some extent by the angular shape of the copper slag aggregate as discussed later. It is interesting that [25] also found a decrease in workability when fine aggregate was replaced by copper slag, against initial expectations. Overall however the workability results show 

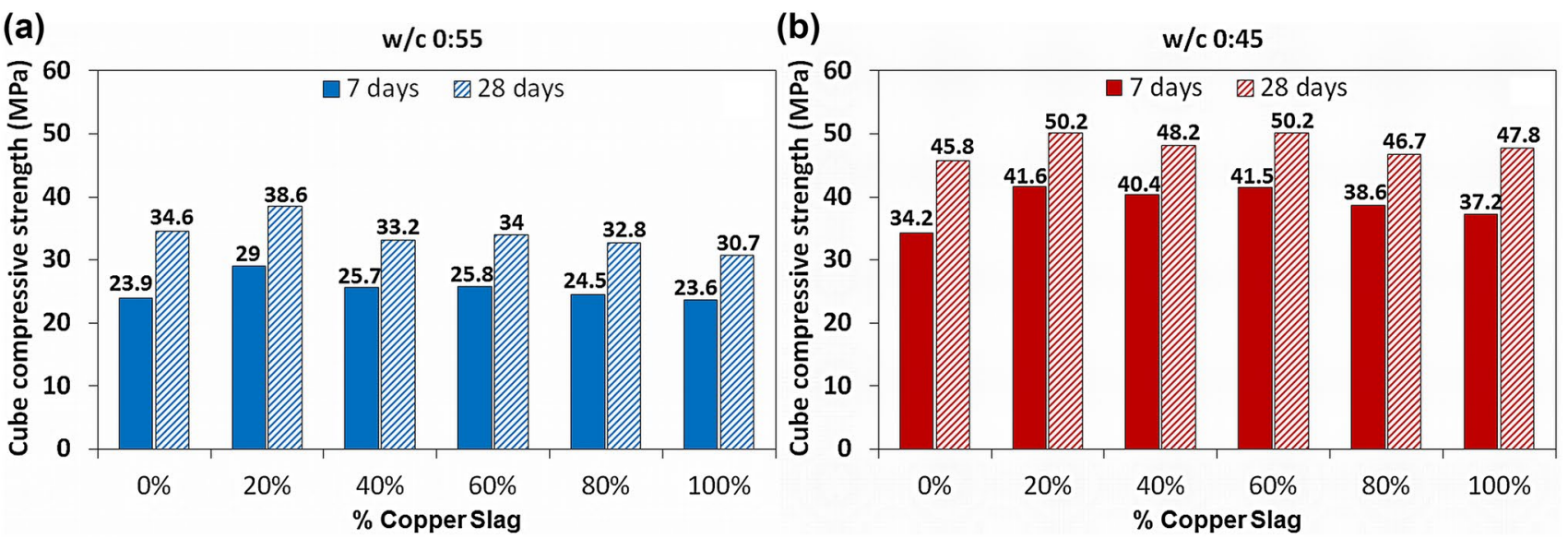

Fig. 37 and 28-days curing compressive strengths of mixes: $\mathbf{a}$ w/c $=0.55 ; \mathbf{b} \mathrm{w} / \mathrm{c}=0.45$

that workable mixes can be achieved for all sand replacement levels if the w/c ratio is carefully controlled.

\section{Hardened Concrete Properties}

\section{Cube Compressive Strength Tests}

Figure $3 \mathrm{a}$ and $\mathrm{b}$ show respectively the 7 and 28 day average cube compressive strengths for different regular sand replacement levels and mixes of $\mathrm{w} / \mathrm{c}=0.55$ and $\mathrm{w} / \mathrm{c}=0.45$ respectively. It can be seen that the effect of the copper slag is variable, as strength may either increase (this is the case for the $w / c=0.45$ mixes and most 7 day curing mixes with $\mathrm{w} / \mathrm{c}=0.55$ ) or decrease (see most 28 day strengths of mixes with $w / c=0.55)$. However most differences in strengths compared to the respective control mixes for 0.55 and 0.45 $\mathrm{w} / \mathrm{c}$ ratios are generally small for most slag percentages and could be due to the usual variability in the concrete batches around a mean value, rather than any significant trends. This observation will be further investigated statistically in "Statistical Analysis" section of the paper. Table 5 represents the evolution of compressive strength between 7 and 28 days based on the ratio of the 7 day curing strength $f_{c 7}$ and that of the 28 day curing $\mathrm{f}_{\mathrm{c} 28}$ of the tested mixes. It can be seen that the evolution follows the usual expected pattern of normal concrete for which, as a rule of thumb, the 7 day strength is often considered to be about $75 \%$ of the 28 day strength value (for instance Neville [46] shows a seven-day strength of approximately $75 \%$ and $80 \%$ of the 28 day strength for w/c of 0.53 and 0.4 respectively, which is consistent with the results in Table 5).

\section{Tensile Strength Tests}

Figure $4 a, b$ represent the results of 28-day indirect tensile strength testing, i.e. splitting cylinder and flexural strength results respectively. Although concrete is usually not designed for tensile strength an indication of this property is useful as it is linked to concrete cracking. The flexural strength of concrete in particular (also known as Modulus of Rupture, MoR), concerns strength in tension of a beam or slab and shows when cracking will develop upon bending. It is therefore relevant for structures such as highway and airfield pavements loaded in bending and hence designed on the basis of the flexural strength of concrete. From Fig. $4 \mathrm{a}$ it can be seen that the splitting tensile strength $\left(f_{t}\right)$ results are as expected for normal concrete, i.e. overall consistent with the compressive strength results in particular for the $w / c=0.55$ mixes, which were all around $7 \%$ of the compressive strength $\left(f_{c}\right)$ results; those of the $w / c=0.45$ were all around $5.5-6 \%$ of the compressive strength with a slightly higher scatter. Using both sets of data a very strong correlation with the compressive strength was found as shown in Fig. 4c. The flexural strengths of the mixes (Fig. 4b) were also overall consistent with the cube compressive strengths trends as in the case of normal concrete, again showing a very strong correlation with the compressive strength (see Fig. 4d); more particularly the 0.45 mixes

Table 5 Compressive strength $\left(f_{c}\right)$ evolution between 7 and 28 daycuring

\begin{tabular}{lll}
\hline Copper slag (\%) & $\mathrm{f}_{\mathrm{c} 7} / \mathrm{f}_{\mathrm{c} 28}$ & \\
\cline { 2 - 3 } & $\mathrm{w} / \mathrm{c}=0.55$ & $\mathrm{w} / \mathrm{c}=0.45$ \\
\hline 0 & 0.75 & 0.75 \\
20 & 0.75 & 0.83 \\
40 & 0.77 & 0.84 \\
60 & 0.76 & 0.83 \\
80 & 0.75 & 0.83 \\
100 & 0.77 & 0.78
\end{tabular}



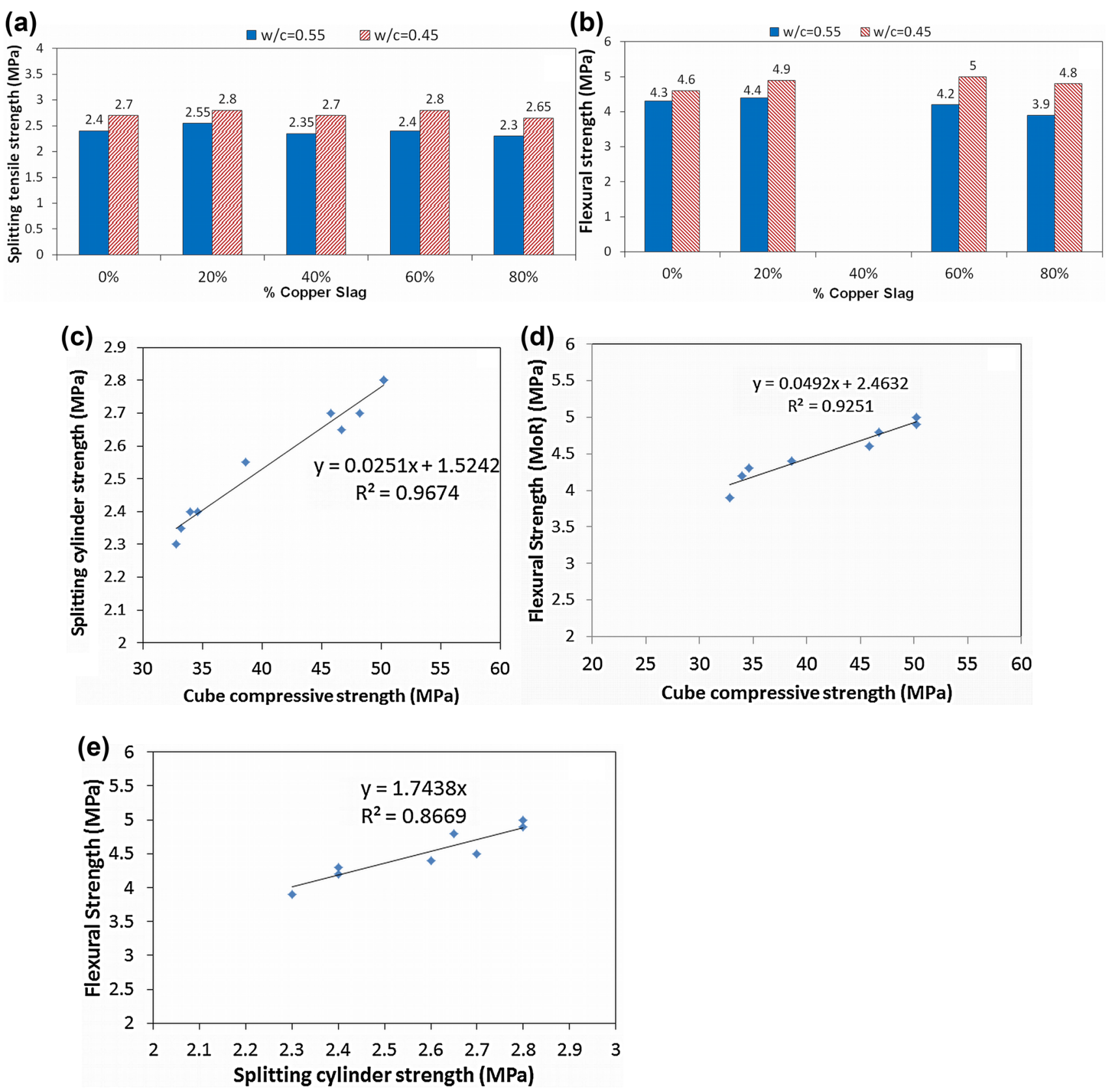

Fig. 4 Indirect tensile strength tests: a splitting tensile strength; b flexural strength; c correlation of splitting cylinder strength with cube compressive strength; d correlation of flexural strength with cube

had flexural strengths of about $10 \%$ of the respective compressive strengths, a value consistent with common empirical rules of thumb regarding the relationship between the tensile strength and compressive strength of normal concrete. For the $\mathrm{w} / \mathrm{c}=0.55$ mixes the ratio of flexural to compressive strength was found in this instance to be higher, i.e. approximately $11-12 \%$ of the compressive strength, which is still within expected flexural strength values as a proportion of the compressive compressive strength; e correlation of splitting cylinder strength with flexural strength

strength. As expected, there is a very strong correlation between the splitting and flexural strengths, as they both constitute different indirect measures of the tensile concrete strength (see Fig. 4e).

\section{Static Modulus of Elasticity}

The results shown in Fig. 5a, $b$ refer to static moduli of elasticity, $\mathrm{E}_{\mathrm{c}}$ (a property crucial to the long-term serviceability 
(a)

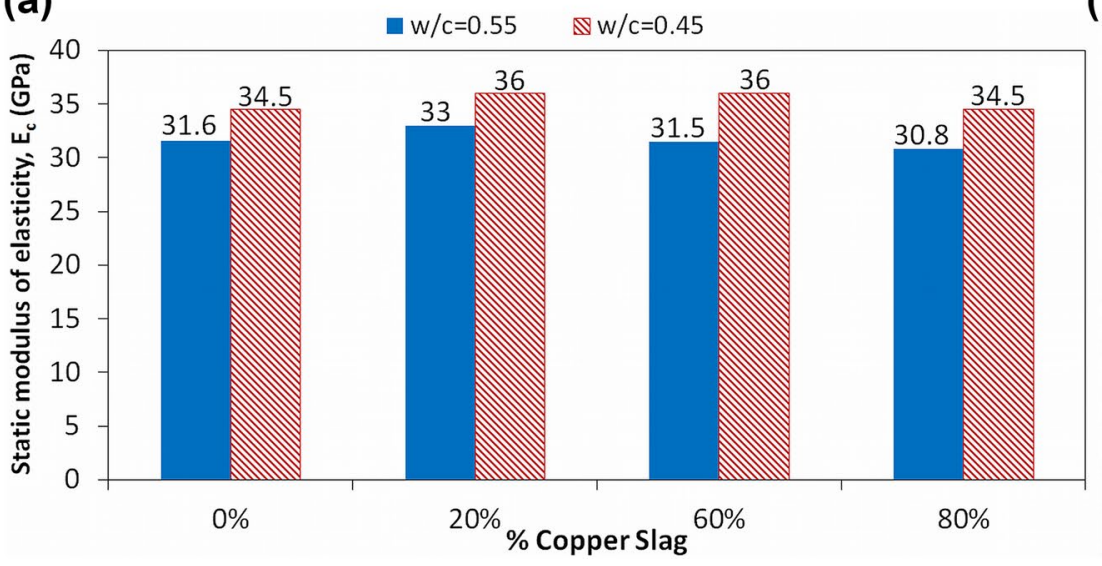

(b)

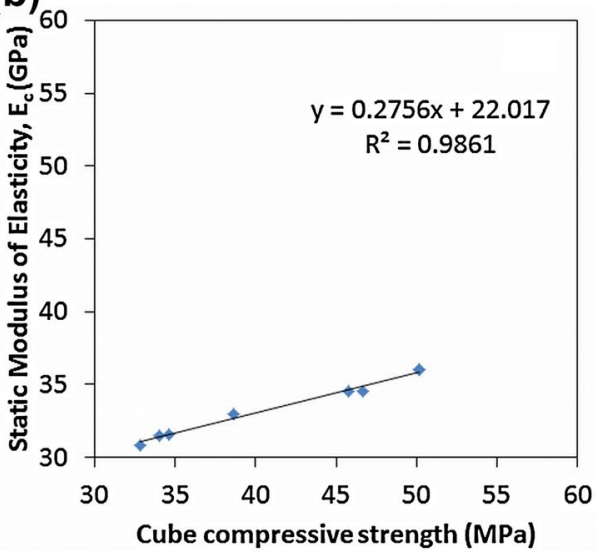

Fig. 5 Static modulus of elasticity tests: a Static modulus of elasticity values; $\mathbf{b}$ correlation of static modulus of elasticity with cube compressive strength

Fig. 6 Water absorption of 28-days cured cubes

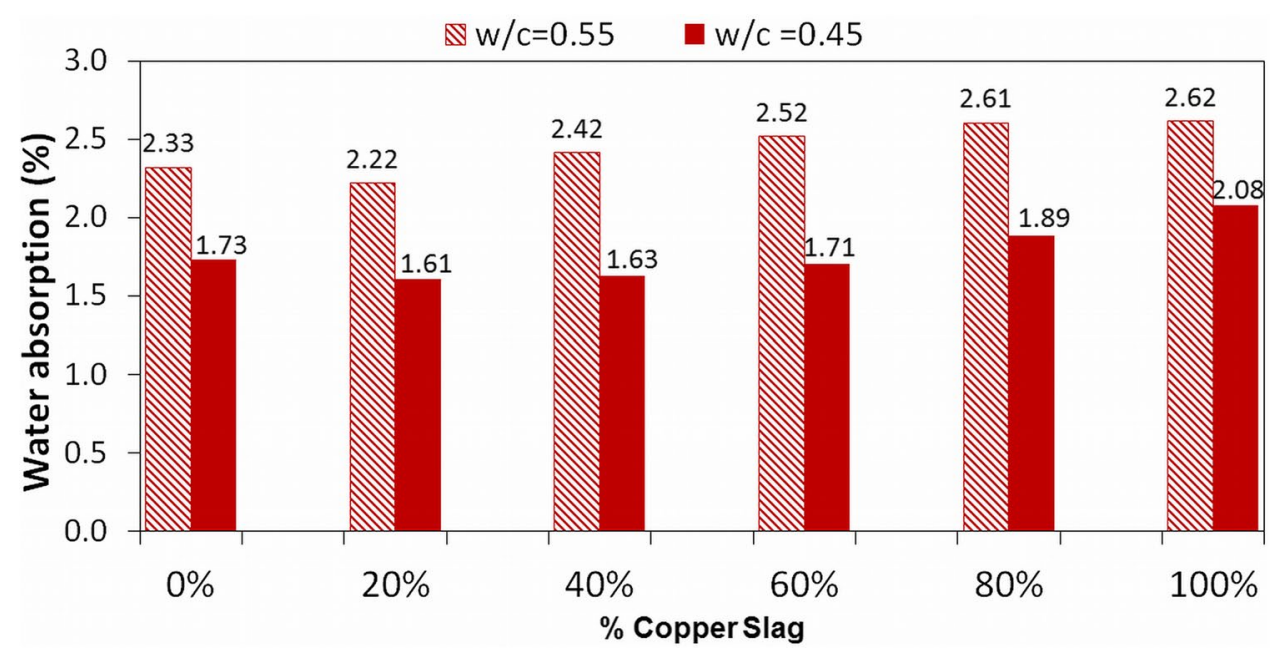

of concrete). They were obtained from cylinders subsequently used to determine the splitting tensile strength (presented earlier). It can be seen that the copper slag concrete has similar or higher moduli of elasticity in comparison to the control mixes (see Fig. 5a), and that the $\mathrm{E}_{\mathrm{c}}$ values show a very strong correlation with the compressive strength results of this study (see Fig. 5b), as expected for regular concrete; the measured values of $\mathrm{E}_{\mathrm{c}}$ are also fairly consistent with empirical expressions where $E_{c}$ is given as a function of the compressive strength [see e.g. 46, 47].

\section{Durability Testing}

\section{Water Absorption Tests}

Figure 6 shows the average absorption results of duplicate specimens. It can be seen that all $0.55 \mathrm{w} / \mathrm{c}$ ratio mixes with copper slag had an increased water absorption compared to the control mix, with the exception of the $20 \%$ CS mix. On the other hand the w/c $=0.45$ mixes had a lower water absorption compared to the respective control mix, with the exception of the two mixes with the highest CS percentages ( 80 and $100 \%$ respectively). It should be noted however that all mixes maintained low water absorptions of less than $3 \%$, which is within expected limits for good durability with respect to liquid ingress in concrete [46]. Other researchers (e.g. Al-Jabri et al. [20] using a w/c =0.5) also found an initially lower water absorption (in [20] this occurred for up to $40 \%$ CS content), which gradually increased above that of the control mix for higher copper slag percentages. It is possible that the increase in water absorption, which was observed mostly in the $\mathrm{w} / \mathrm{c}=0.55$ mixes was due to some excess water (the copper slag particles having a lower surface water absorption than sand); this could lead to a higher porosity and could explain both the higher absorption and 


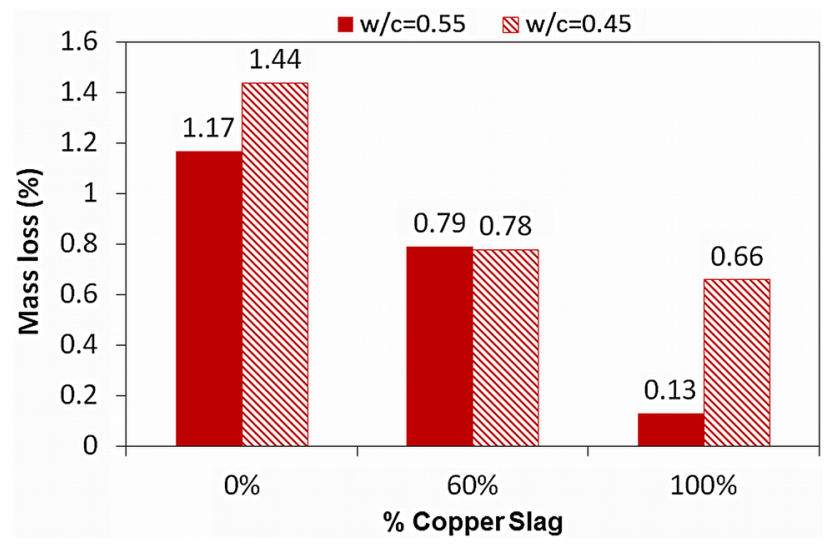

Fig. 7 Accelerated corrosion testing results

Table 6 Recorded carbonation depths of different mixes

\begin{tabular}{|c|c|c|c|c|}
\hline \multirow{2}{*}{$\begin{array}{l}\text { Copper } \\
\text { slag (\%) }\end{array}$} & \multicolumn{2}{|l|}{ w/c 0.45} & \multicolumn{2}{|l|}{ w/c 0.55} \\
\hline & $\begin{array}{l}\text { Average depth } \\
\text { of carbonation, } \\
\mathrm{d}_{\text {kmean }} \\
(\mathrm{mm})\end{array}$ & $\begin{array}{l}\text { Isolated } \\
\text { pockets } \\
\mathrm{d}_{\mathrm{kmax}} 1 \\
(\mathrm{~mm})\end{array}$ & $\begin{array}{l}\text { Average depth } \\
\text { of carbonation, } \\
\mathrm{d}_{\text {kmean }} \\
(\mathrm{mm})\end{array}$ & $\begin{array}{l}\text { Isolated } \\
\text { pockets } \\
\mathrm{d}_{\mathrm{kmax}} \\
(\mathrm{mm})\end{array}$ \\
\hline 20 & 0.5 & $(2.5,6)$ & 1.5 & (3.5) \\
\hline 40 & $<0.5$ & - & 3 & - \\
\hline 60 & 1.5 & - & 1 & - \\
\hline 80 & 2 & - & 2 & (4) \\
\hline
\end{tabular}

${ }^{1}$ The isolated pocket maximum carbonation depths have been recorded and reported but not considered in the calculation of the $\mathrm{d}_{\mathrm{kmean}}$ as prescribed in the standard [43]

the comparatively lower respective compressive strength of the affected mixes.

\section{Accelerated Corrosion Testing Results}

Figure 7 represents the accelerated corrosion test results in terms of mass loss of the embedded steel reinforcement bars. It can be observed that both control mixes (of w/c ratios of 0.45 and 0.55 respectively) had a higher corrosion (based on the higher mass loss of the bars) than the mixes with copper slag. The highest corrosion was found for the 0.45 control mix which also showed some surface cracking of the concrete adjacent to the reinforcing bar. On the other end, the w/c 0.55 mix with $100 \%$ CS showed a minute mass loss. The results indicate that using water-cooled copper slag as a replacement of fine aggregate increased the corrosion resistance of the resulting concrete compared to concrete with natural fine aggregate. Note that the opposite trend was shown in Brindha et al. [23] for air-cooled copper slag used for up to $50 \%$ sand replacement levels, where increasing CS percentages showed a small increase in the corrosion rate compared to the control mix.
Carbonation Testing Results

According to the phenolphthalein test, if there is no carbonation and the concrete is highly alkaline a vivid purple colour is obtained after the spraying of the concrete with the solution. Most mixes showed almost no signs of carbonation except for some local carbonation mostly around microcracks or aggregates, which is consistent with concurrent research findings by [25]. The results of the average carbonation depths $d_{\text {kmean }}$ (recorded to the nearest $0.5 \mathrm{~mm}$ ) of the tested copper slag mixes for duplicate specimens per mix are presented in Table 6 . These show a similar performance to that of normal concrete and increasing carbonation depths as w/c increases. For instance results reported for normal concrete can commonly range between $1 \mathrm{~mm}$ to over $3 \mathrm{~mm}$ per year [46]. For limestone cement concrete in particular (i.e. the cement type used in this study) depths of carbonation of 3.2 and $4.6 \mathrm{~mm}$ for w/c of 0.45 and 0.55 respectively were recently reported in the literature [48] (after 7 days of accelerated carbonation).

\section{Alkali-Silica Reaction Testing}

The test assessed the possibility of a reaction of the alkalis in cement as well as compounds in the copper slag such as $\mathrm{K}_{2} \mathrm{O}$ and $\mathrm{Na}_{2} \mathrm{O}$ with silica from the amorphous water cooled copper slag aggregate. This reaction between alkalis contained in Portland cement and aggregate containing a reactive form of silica (i.e. any kind of silica that can dissolve in cement paste) can lead to a serious degradation of the concrete; after dissolution, silica can react with sodium/ potassium ions contained in the cement paste to form a gel which appears on the surface of the aggregate; this gel attracts water which leads to an expansion causing concrete to crack. The test was conducted on duplicate mortar bar specimens of CEM-II containing respectively $0 \%$ (control mix) and 100\% copper slag (considering that 100\% CS would constitute a worst-case scenario if the copper slag aggregate was reactive). Very minute expansions, all well below the ASTM limit of 0.1\% [45] were recorded throughout the testing period, implying that the slag is innocuous.

\section{Statistical Analysis}

Compressive strength is an important factor in designing and optimising concrete mixes and for designing structural elements. Moreover, as discussed earlier, other mechanical properties can be correlated with compressive strength. For this reason some further statistical investigation using $\mathrm{R}$ software was performed on the 28-day compressive strength results in order to assess any possible significant trends; 28-day compressive strength was chosen for 
analysis as this is the usual industry-wide basis for consistent comparisons of the compressive strength of concrete products. In the analyses datasets of 28-compressive strengths from Mavroulidou and Liya [32] were also included, to provide an additional factor to consider in the analysis, i.e. the cement type; the results in [32] were based on a different type of cement (CEM-I) but considered the same two w/c ratios, i.e. 0.45 and 0.55 . The analysis was in the form of $\mathrm{n}^{\mathrm{k}}$ factorial experiments (with replication) with the number of factors $\mathrm{k}=3$ and two levels of the factors $(n=2)$, i.e. copper slag content (the two levels assigned were -1 (low) and +1 (high)), water/cement (w/c) ratio (0.45 and 0.55 factor levels) and the categorical factor "cement type" (CEM-I and CEM-II factor levels). Boxplots, histograms and normal probability Quantile-Quantile (QQ) plot of the dataset (not shown here for brevity) showed that the normality assumption would be appropriate; this was confirmed by Shapiro-Wilk normality test (the $\mathrm{p}$-value $=0.9334 \mathrm{did}$ not reject the null hypothesis of the test that data were from a normally distributed population). However the Fligner-Killeen test of homogeneity of variances rejected the null hypothesis that variances are equal (a second assumption of ANOVA) as it returned a $\mathrm{p}$-value $=0.03656$ (this remained the case even after different transformations of the data). With this reservation in mind ANOVA tests were performed considering main effects and binary interactions between factors but the outcomes were cross-checked with Kruskal-Wallis non-parametric analysis. The ANOVA results showed that $\mathrm{w} / \mathrm{c}$ is the most statistically significant factor $\left(p=2.493 \times 10^{-6}\right)$ followed by the cement type $\left(\mathrm{p}=1.139 \times 10^{-4}\right)$. On the other hand the level of copper slag was found to have no statistically significant effect $(p=0.2087304)$. No significant interaction effects were found $(p=0.2208567$, $\mathrm{p}=0.9216146$ and $\mathrm{p}=0.7191864$ respectively for the copper slag-w/c ratio, copper slag-cement type and w/c ratiocement type interactions). As there are no interaction effects, the main effects discussed above are meaningful. Quality control of the ANOVA model (boxplot and normal Quantile-Quantile (QQ) plots), which is not shown here for brevity, found the residuals to reasonably follow a normal distribution (as required); this was confirmed by Shapiro-Wilk normality test on the residuals ( $\mathrm{p}$-value $=0.3587$ ). Finally, the plot of residuals vs. fitted values showed a rather random pattern with residuals plotting on both sides of 0 without any obvious relationship between the size of the fitted value and the variance of the residuals, which is the desired outcome. The non-parametric Kruskal-Wallis analysis of the main effects confirmed that copper slag content is not statistically significant ( $p$-value $=0.7927$ ), and that the w/c was the most significant factor with a $\mathrm{p}$-value $=0.001122$ for a confidence interval of $95 \%$; on the other hand the Kruskal-Wallis analysis found cement type to be significant at a lower confidence interval only ( $p$-value $=0.07399)$. Whereas the significant effect of the w/c and cement type factors was expected, the lack of significant effect of the copper slag content (which was of particular interest in this study) was further investigated and supported by one-way analysis of variance using the two entire datasets of 28 days cube compressive strength results of CEM-II for the 0.55 and $0.45 \mathrm{w} / \mathrm{c}$ ratios respectively (with four replications). Kruskal-Wallis one-way analysis of variance, ${ }^{1}$ confirmed copper slag level to be of no statistical significance $(p=0.19$ and $p=0.2838$ for the 0.55 and $0.45 \mathrm{w} / \mathrm{c}$ ratio datasets respectively).

\section{Discussion}

The above tests showed that most concrete properties are insensitive to the incorporation of copper slag from 0 to $100 \%$ replacement levels. Some justification of these findings is offered here as follows: firstly, the consistence of concrete is controlled by a large number of factors such as particle size and distribution, particle shape and texture as well as particle water absorption. In this case the two aggregates (copper slag and natural river sand) have essentially similar Particle Size Distributions (PSD), hence sizes, uniformities and fineness moduli, which are related to their packing. The particle shape and surface texture of an aggregate influence the properties of freshly mixed concrete more than the properties of hardened concrete. In this case the natural aggregate and the copper slag were both of a smooth texture however the latter particles were angular as opposed to the subrounded river sand particles; the angularity, which usually reduces workability making concrete harsh and the increased frictional resistance of the particles may therefore partly counterbalance the effect of lower water absorption (which would imply higher free water in the mix hence a potentially higher workability) compared to the natural aggregate. In addition the bonding between cement paste and a given aggregate generally increases as particles change from subrounded to angular. This increase in bonding could explain the good strengths (compressive and tensile) of the copper slag concrete mixes (as noted earlier strength changes linked to the addition of copper slag were not found to be statistically significant). This is despite the reduced water absorption of the copper slag aggregate which would imply higher free water in the mix (and which would negatively affect strengths) and the glassy surface expected to have a negative effect on the bonding. It is possible that the results were partly affected

\footnotetext{
${ }^{1}$ Due to severe departures from normality in both the original dataset and the residuals the ANOVA model results are not reported.
} 
by some segregation and bleeding which was noticed; this is consistent with the somewhat increased water absorption of the resulting concrete (still however of low values) at higher copper slag contents as excess water and bleeding can increase the porosity. For the lower w/c ratio mixes, the relatively higher water absorption of the resulting concrete could also be due to the drier and hence more porous mix (consistent with the lower slump) when high percentages of slag were used. To optimise the mixes and reduce this effect, further study on the water demand of the mixes is required. Nevertheless, the overall good durability performance of the copper slag concrete, which was observed in these tests, is consistent with the generally adequate physico-chemical characteristics of the copper slag. From the above discussion the use of copper slag as fine aggregate replacement can therefore be considered as promising overall.

\section{Conclusions}

Current focus on sustainable construction leads to the intensive search for alternative materials to be used as aggregates in concrete production. Copper slag, the waste material produced in the extraction process of copper metal in refinery plants, has a number of physical characteristics similar to that of natural sand; it can thus be a potentially good candidate for use as a fine aggregate in concrete production with many environmental benefits, such as waste recycling and the avoidance of landfilling, as well as a reduction in the need for using non-renewable natural aggregate. The paper presented a comprehensive parametric study on the effects of water-cooled copper slag on a wide range of fresh and hardened concrete properties and durability characteristics of concrete, where copper slag was used as fine concrete aggregate replacement. The results showed that:

- Overall, mixes with the tested copper slag percentages had strengths and measured moduli of elasticity (for which there is lack of data in the literature) comparable to those of normal concrete and showing the expected trends (i.e. good correlations of compressive strengths with indirect tensile strengths and moduli of elasticity; these complied fairly well with suggested empirical correlations of such properties with compressive strengths for regular concrete, included in a number of standards or guidelines).

- Statistical analysis confirmed that there was no significant effect on the compressive strengths of concrete (the fundamental property for concrete design) and no interaction effects between water content, cement type and copper slag levels regarding the compressive strengths obtained; as with regular concrete the most influential factor for concrete strength was found to be the w/c ratio.

- Durability of concrete in terms of reinforcement corrosion, depth of carbonation, and the possibility of deleterious alkali-silica reactions was also found in general to be similar or better to that of normal concrete; the water absorption performance of the copper slag concrete was overall also fairly similar to that of the control mixes; the values fluctuated around that of the respective control mix value, slightly increasing at the highest copper slag replacement levels.

- On the other hand the effects of copper slag on fresh concrete workability were variable and the lower w/c mixes in particular were adversely affected by the increase in copper slag content; such issues could however be addressed by optimising the mixes by adjusting the w/c ratio and/or using superplasticisers. This was beyond the scope of this study.

Based on the above findings it can therefore be concluded that upon further mix optimisation this type of aggregate can be used as a suitable substitute for natural sand. Eventually, as for any other cases where waste materials are suggested for use in concrete, the viability of using this aggregate in concrete will depend on local economics, i.e. cost, availability of the material in sufficiently large quantities and availability and costs of similar natural aggregates in the respective regions where concrete production plants operate. Nonetheless with the depletion of the natural aggregates, the use of suitable alternative aggregates based on waste materials should be encouraged as a potentially more sustainable option overall.

Acknowledgements The study was conducted at the Concrete and Materials Laboratory of London South Bank University (LSBU), using resources fully provided by LSBU. A large part of the experimental results were obtained by Mr Tomasz Kobylinski; the physical properties of the aggregates were determined by Mr Christopher Gray. The assistance of Ms Catherine Unsworth and Mr Graham Bird during the testing is gratefully acknowledged.

Open Access This article is distributed under the terms of the Creative Commons Attribution 4.0 International License (http:// creativecommons.org/licenses/by/4.0/), which permits unrestricted use, distribution, and reproduction in any medium, provided you give appropriate credit to the original author(s) and the source, provide a link to the Creative Commons license, and indicate if changes were made.

\section{References}

1. Shi, C., Meyer, C., Behnood, A.: Utilization of copper slag in cement and concrete. Resour. Conserv. Recy. 52(10), 1115-1120 (2008) 
2. Lye, CQ., Koh, SK., Mangabhai, R., Dhir, R.: Use of copper slag and washed copper slag as sand in concrete: a state-of-the-art review. Mag. Concrete Res. 67(12), 665-679 (2015)

3. Gorai, B., Jana, R.K.: Characteristics and utilisation of copper slag-a review. Resour. Conserv. Recy. 39, 299-313 (2003)

4. De Britto, J., Saikia, N.: Recycled aggregate in concrete. Use of industrial, construction and demolition waste. Springer, London (2013)

5. Shanmuganathan, P., Lakshmipathiraj, P., Srikanth, S., Nachiappan, A., Sumathy, A.: Toxicity characterization and long-term stability studies on copper slag from the ISASMELT process. Resour. Conserv. Recy. 52 (4), 601-611 (2008)

6. Brindha, D., Nagan, S.: Durability studies on copper slag admixed concrete. Asian J. Civil Eng. (Building and Housing). 12(5), 563-578 (2011)

7. Khanzadi, M., Behnood, A.: Mechanical properties of highstrength concrete incorporating copper slag as coarse aggregate. Constr. Build. Mater. 23(6), 2183-2188 (2009)

8. Erdem, S., Dawson, A. R., Thom, N. H.: Influence of the microand nanoscale local mechanical properties of the interfacial transition zone on impact behavior of concrete made with different aggregates. Cem. Concr. Res. 42, 447-458 (2012)

9. Fadaee, M., Mirhosseini, R., Tabatabaei, R., Fadaee, M. J.: Investigation of using copper slag as part of cementitious materials in self-compacting concrete. Asian J. Civil Eng. (BHRC). 16(3), 368-381 (2015)

10. Najimi, M., Sobhani, J., Pourkhorshidi, A.R.: Durability of copper slag contained concrete exposed to sulfate attack. Constr. Build. Mater. 25, 1895-1905 (2011)

11. Madheswaran, C. K., Ambily, P. S., Dattatreya, J. K., Rajamane, N. P.: Studies on use of Copper Slag as Replacement Material for River Sand in Building Constructions. J. Inst. Eng. India Ser. A 95(3):169-177 (2014)

12. Chockalingam, M., Jayganesh, D., Vijayaraghavan, J., Jegan, J.: Scope for reuse of copper slag in concrete-A review. Int. J. Civil Eng. Technol. 4(6), 89-100 (2013)

13. Buddhadev, C., Pitroda, J., Vyas, C., M.: A review of innovative use of copper slag and foundry sand in design mix concrete. J. Int. Acad. Res. Multidiscip. 2(12) (2015)

14. Murari, K., Siddique, R., Jain, K. K.: Use of waste copper slag, a sustainable material. J. Mater Cycles Waste Manag. 17, 13-26 (2015)

15. Saxena, P., Simalti, A.: Scope of replacing fine aggregate with copper slag in concrete $-\mathrm{A}$ review. Int. J. Tech. Res. Appl. 3(4), 44-48 (2015)

16. Dhir, R.K., de Brito, J., Mangabhai, R., Lye, C.Q.: Sustainable Construction Materials-Copper Slag, Woodhead Publishing, Cambridge (2017)

17. Al-Jabri, K.S.: Copper slag as fine aggregate for high performance concrete. WIT Trans. Built Environ. 85, 381-389 (2006) http://www.witpress.com. Accessed 27 Feb 2016

18. Al-Jabri, K.S., Hisada, M., Al-Saidy, A.H., Al-Oraimi, S.K.: Performance of high strength concrete made with copper slag as a fine aggregate. Constr. Build. Mater. 23(6), 2132-2140 (2009)

19. Al-Jabri, K.S., Hisada, M., Al-Oraimi, S.K., Al-Saidy, A.H.: Copper slag as sand replacement for high performance concrete. Cement Concr. Compos. 31(7), 483-488 (2009)

20. Al-Jabri, K.S., Al-Saidy, A.H., Taha, R.: Effect of copper slag as a fine aggregate on the properties of cement mortars and concrete. Constr. Build. Mater. 25(2), 933-938 (2011)

21. Gowda, D.B., Balakrishna, H. ,B.: Experimental study on flexural behavior of reinforced concrete beams by replacing copper slag as fine aggregate, Int. J. Civil Struct. Eng. Res 2(1), 97-103 (2014) http://www.researchpublish.com. Accessed 2 March 2016

22. Kiran Kumar, M.S., Naik. R.: Experimental study on utilization of industrial wastes (red mud and copper slag) in mortar and concrete. Int. J. Civil Struct. Eng. Res. 3(1), 228-233 (2015) http://www.researchpublish.com. Accessed 2 March 2016

23. Brindha, D., Baskaran, T., Nagan, S.: Assessment of corrosion and durability characteristics of copper slag admixed concrete. Int. J. Civil Struct. Eng. 1(2), 192-211 (2010)

24. Poovizhi, T., Kathirvel, P.: Behaviour of concrete with partial replacement of copper slag as cement and fine aggregate. Trans. Eng. Sci. 3(2), 30-35 (2015)

25. De Schepper, M., Verlé, P., Van Driessche, I., De Belie, N.: Use of secondary slags in completely recyclable concrete. J. Mater. Civ. Eng. 27(5), 1-9 (2015)

26. Kharade, A.S., Kapadiya, S.V., Chavan, R.: An experimental investigation of properties of concrete with partial or full replacement of fine aggregates through copper slag. Int. J. Eng. Res. Technol. (IJERT) 2(3): 1-10 (2013) http://www.ijert.org. Accessed 2 March 2016

27. Thomas, B.S., Damare, A., Gupta, R.C.: Strength and durability characteristics of copper tailing concrete. Constr. Build. Mater. 48, 894-900 (2013)

28. Onuaguluchi, O., Eren, O.: Copper tailings as a potential additive in concrete: Consistency, strength and toxic metal immobilization properties. Indian J. Eng. Materials Sci 19(2), 79-86 (2012)

29. Ayano, T., Kuramoto, O., Sakata, K.: Concrete with copper slag fine aggregate. J. Soc. Material Sci. Japan 49(10), 1097-1102 (2000)

30. Lee, M.H.: A study on the evaluation of the durability of concrete using copper slag aggregates. J. Korea Concr. Inst. 20(6), 773-784 (2008)

31. Wu, W., Zhang, W., Ma, G.: Optimum content of copper slag as a fine aggregate in high strength concrete. Mater. Des. 31(6), 2878-2883 (2010)

32. Mavroulidou, M., Liya, N.: Properties of concrete containing waste copper slag as fine aggregate replacement. Proceedings of the 14th International Conference on Environmental Science and Technology CEST2015, Rhodes Greece, 3-5 September 2015 http://cest.gnest.org/cest15proceedings/public_html/papers (2015). Accessed 10 Oct 2015

33. British Standards Institution (BSI): BS 812-2:1995: Testing aggregates Part 2. Methods of determination of density. BSI, London (1995)

34. British Standards Institution (BSI): BS 5238-1:1997: ConcretePart 1: Guide to specifying concrete. BSI, London (1997)

35. British Standards Institution (BSI): BS EN 12390-2: 2009. Testing hardened concrete, Part 2: Making and curing specimens for strength tests. BSI, London (2009)

36. British Standards Institution (BSI): BS EN 12350-2:2009: Testing fresh concrete. Part 2: Slump test. BSI, London (2009)

37. British Standards Institution (BSI): BS EN 12390-3:2009: Testing hardened concrete -Part 3: Compressive strength of test specimens. BSI, London (2009)

38. British Standards Institution (BSI): BS EN 12390-6:2009: Testing hardened concrete - Part 6: Tensile splitting strength of test specimens. BSI, London (2009)

39. British Standards Institution (BSI): BS EN 12390-5:2009: Testing hardened concrete -Part 5: Flexural strength of test specimens. BSI, London (2009)

40. British Standards Institution (BSI): BS 1881-121:1983: Testing concrete -Part 121: Method for determination of static modulus of elasticity in compression. BSI, London (1983)

41. British Standards Institution (BSI): BS 1881-122:1983: Testing Concrete - Part 122: Method for deternimation of water absorption. BSI, London (1983)

42. Malumbela, G., Moyo, P., Alexander, M.: A step towards standardising accelerated corrosion tests on laboratory reinforced concrete specimens. J. S. Afr. Inst. Civil Eng. 54 (2), 78-85 (2012) 
43. American Society of Testing and Materials (ASTM): Standard Practice for Preparing, Cleaning, and Evaluating Corrosion Test Specimens, ASTM G1-90, G01 Committee ASTM International, American Society for Testing and Materials, Designation G1599b (Revised) 03.02.2000. ASTM, West Conshohocken (2000)

44. British Standards Institution (BSI): BS EN 14630: 2006, Products and systems for the protection and repair of concrete structure-Test Methods-Determination of carbonation depth in hardened concrete by the Phenolphthalein method. BSI, London (2006)

45. American Society of Testing and Materials (ASTM): Standard test method for potential alkali reactivity of aggregates
(Mortar-Bar Method). ASTM C1260-01, Annual Book of ASTM Standards, vol. 04.02.2003. ASTM, West Conshohocken (2003)

46. Neville, A.M.: Properties of concrete. 4th edn, Longman, London (1995)

47. European Ready Mixed Concrete Organisation (ERMCO): Guidance to the engineering properties of concrete. ERMCO, Brussels (2006)

48. McNally, C., Sheils, E.: Probability-based assessment of the durability characteristics of concretes manufactured using CEM II and GGBS binders. Constr. Build. Mater. 30(5), 22-29 (2012) 